\title{
Re-Estimation of a Plausible Model of the Earthquake Fault as the Source of the 1771 Great Meiwa Tsunami Based on the Assessment of the Run-Up Height by Okinawa Prefecture, Japan
}

\author{
Takeshi Matsumoto \\ Faculty of Science, University of the Ryukyus, Okinawa Prefecture, Japan \\ Email: tak@sci.u-ryukyu.ac.jp
}

How to cite this paper: Matsumoto, T. (2020) Re-Estimation of a Plausible Model of the Earthquake Fault as the Source of the 1771 Great Meiwa Tsunami Based on the Assessment of the Run-Up Height by Okinawa Prefecture, Japan. Open Journal of Geology, 10, 1250-1261.

https://doi.org/10.4236/ojg.2020.1012062

Received: November 27, 2020

Accepted: December 28, 2020

Published: December 31, 2020

Copyright $\odot 2020$ by author(s) and Scientific Research Publishing Inc. This work is licensed under the Creative Commons Attribution International License (CC BY 4.0).

http://creativecommons.org/licenses/by/4.0/

\begin{abstract}
Plausible parameters of the earthquake fault which caused the 1771 Great Meiwa Tsunami were re-estimated by comparing the result of the tsunami run-up height by the numerical simulation by Okinawa Prefectural Government and those by 1) run-up height derived from previous field works, and 2) a historical record describing the run-up height in Miyako District. The re-estimation shows that the length of the fault off Miyako and Yaeyama districts is $300 \mathrm{~km}$ or more. However, the slip of the fault is $20 \mathrm{~m}$ off Yaeyama and 8 - $14 \mathrm{~m}$ off Miyako.
\end{abstract}

\section{Keywords}

The 1771 Great Meiwa Tsunami, Okinawa, Earthquake Fault

\section{Introduction and Previous Works}

The 1771 Great Meiwa tsunami (Yaeyama Earthquake Tsunami, hereafter referred as "The 1771 Tsunami") which occurred in the western Ryukyu district on April 24, 1771 caused tremendous damages in the Yaeyama and Miyako districts, with approximately 12,000 casualties. The source area of the 1771 Tsunami has been estimated to be an M7.4-equivalent fault at $24.0^{\circ} \mathrm{N} 124.3^{\circ} \mathrm{E}$ (fore-arc area of the southwestern Ryukyu Islands, about $40 \mathrm{~km}$ south of Ishigaki Island) [1].

The historical record "The Situation in Each Village at the Time of the Big Wave", which was issued just after the 1771 Tsunami by the local government of 
Yaeyama District, clearly describes the tsunami damage situation and maximum run-up heights from each coastal area in the Yaeyama District. Reference [2] by Makino (1968) is a commentary of the historical record, which is of great help for further studies on numerical modelling. However, the run-up heights described in the historical record are considered to be over-estimated such as the maximum height is $85 \mathrm{~m}$ from the Miyara Bay located on the southern coast of Ishigaki Island.

The other approaches to the source area of the 1771 Tsunami are off-shore studies such as bathymetry to detect fault scarps, seismic surveys to detect submarine active faults, and precise seafloor mapping by underwater vehicles. [3] shows the results of bathymetric mapping and seismic reflection surveys as the hydrographic studies of the Japan Coast Guard in the 1970s, and reports the distribution of many submarine active faults in the southwestern Ryukyu area. However, the study area at this time was limited in the area north of $24^{\circ} \mathrm{N}$, therefore, the axial area of the Ryukyu trench off Miyako and Yaeyama districts was not included in the publication. [4] showed the result of bathymetric survey mainly in the area south of $24^{\circ} \mathrm{N}$ including the trench axial area and found fault scarps, relics of underwater landslides as possible tsunami source, and deep-sea canyons as a possible propagator of tsunamis.

These topographic data together with the information of the run-up heights along the coastal area are essential for the studies on the numerical simulation of tsunami propagation to detect the exact source area. However, despite much efforts by many research groups (e.g. [5] [6] [7]), exact solution has not yet been accurately obtained.

The result of [3] includes many active submarine faults in the southwest Ryukyu area. Many of these faults are across-arc normal faults that completely cross the Ryukyu Arc. One of these faults, an NW-SE trending $44 \mathrm{~km}$ submarine normal fault is located about $50 \mathrm{~km}$ off the eastern coast of Ishigaki Island, and is proposed as a possible source of the 1771 Tsunami [8]. However, later through the precise seafloor mapping by ROV survey, this fault was found to include a mature (southernmost tip) and immature (northernmost tip) part and the propagation might occur due to the opening of the Okinawa Trough and roll back of the arc towards the Ryukyu Trench, which suggested it hard to be the source of the 1771 Tsunami [9].

In order to detect the actual run-up heights, the approach of the distribution of the tsunami boulders is also essential. The study [10] described the tsunami boulders in this area and suggested that large-scale tsunami hit the Yaeyama District several times at intervals of 500 - 1000 years, possibly either from south (Ryukyu Trench side) and north (Okinawa Trough side). The amount of the run-up height in the Miyako district is described in the historical record "O-Toiai-Gaki" which was discovered in 1987 [11]. The study [12] by the author verified the description in the record by additional field work in the whole area of the Miyako District and found that most of the descriptions are reliable considering the distribution of the tsunami boulders in this district. A study in order 
to estimate the more plausible run-up heights in both Miyako and Yaeyama districts was carried out [13] by field observations and the interviews together with the description of the historical records, and then the new data were compiled with reliability ranks. The location of these districts is shown in Figure 1 (index map).

Since the 2011 East Japan Earthquake, the existence of earthquake faults spanning several hundred kilometres is to be remarked, and the local governments in Japan re-estimated the tsunami run-up heights assuming an earthquake caused by such a long-range fault. The 1771 Tsunami might be also caused by similar earthquake fault(s) in the western Ryukyu district. Therefore, the Okinawa Prefectural Government of Japan re-estimated the tsunami flooding heights through a numerical simulation and the latest results were released in 2015 (hereafter referred as "The 2015 Tsunami Assessment") [14].

The purpose of this study is to re-estimate the plausible parameters of the earthquake fault(s) which caused the 1771 Tsunami in the 2015 Tsunami Assessment by verifying the results of [11] and [13]. Total 16 earthquake faults were selected to get the maximum flooding heights at all the locations on the coast in Okinawa Prefecture in The 2015 Tsunami Assessment [14]. The description of the historical record "The Situation in Each Village at the Time of the Big Wave", was treated as "reference level" in this study.

\section{About "The 2015 Tsunami Assessment"}

In this assessment, the tsunami flooding, inundation and runup heights were estimated by the numerical simulation based on the Japanese "Tsunami Disaster Prevention Community Development Law" by Civil Engineering and Architecture Department, Okinawa Prefecture, Japan. After the 2011 Tohoku Earthquake

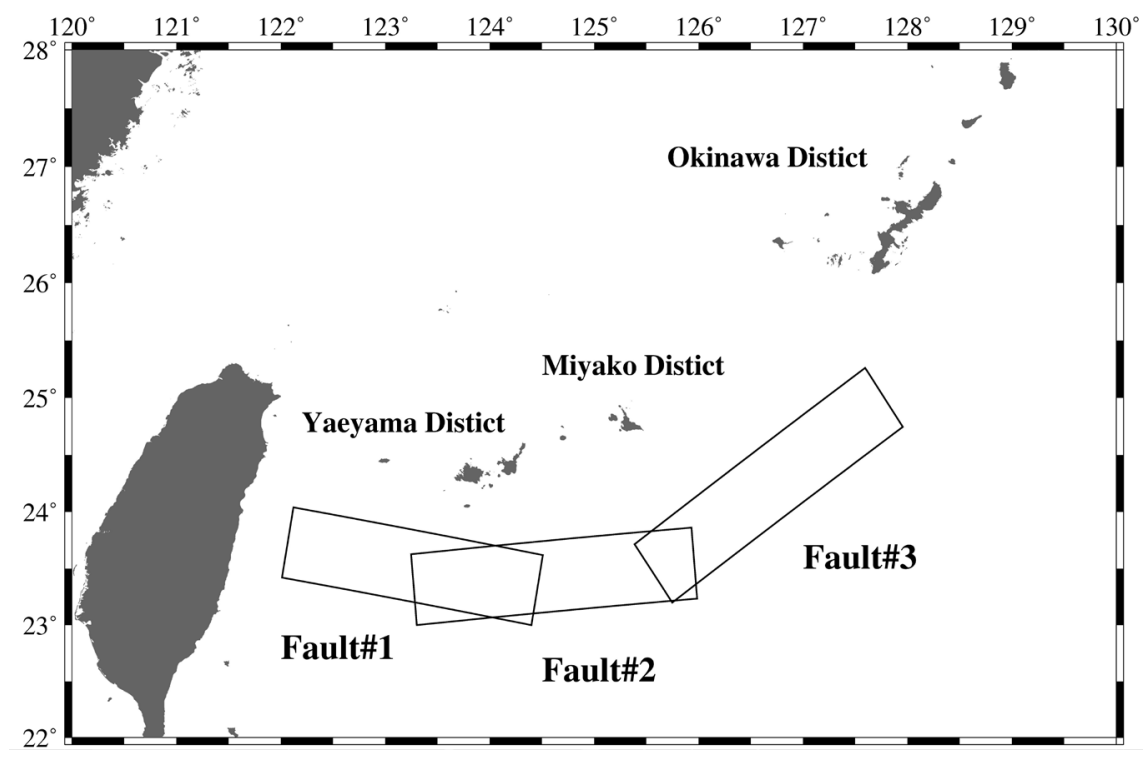

Figure 1. Index map of the Ryukyu-Okinawa area, southwestern part of the Japanese Archipelago. Also shows the district names of the study area and the locations of the Fault number 1 - 3 defined in the 2015 Tsunami Assessment [14] and used in this study. 
and Tsunami, a basic policy for hazard assessment was re-considered in most prefectures in Japan and an impact of a plausible largest-scale tsunami based on the earthquake fault(s) of several hundreds of kilometres in length was taken into account for the assessment of a tsunami hazard. Plausible largest class earthquakes in the Ryukyu (Nanseishoto) Trench area and in the Okinawa Trough side were taken into account as for the wave source model in this assessment.

Considering the damage in Yaeyama District, the most probable tsunami was assumed based on the linkage of three $300 \mathrm{~km}$ faults at the southwestern tip of the Ryukyu Trench (Fault number 16) and a $300 \mathrm{~km}$ fault off Miyako and Yaeyama (Fault number 2). Figure 1 also shows the location of these faults. Table 1 shows the parameters of these faults.

The precision of the topographic data is essential in the numerical simulation of the tsunami inundation estimation. In this assessment, the grid spacing of the topography was modified to be $10 \mathrm{~m}, 30 \mathrm{~m}, 90 \mathrm{~m}, 270 \mathrm{~m}, 810 \mathrm{~m}, 2430 \mathrm{~m}$ from the coastal region towards the off-shore area. The $30 \mathrm{~m}$-gridded topographic data were created mainly from the JTOPO30, M7000, etc., from Japan Coast Guard. The terrain $10 \mathrm{~m}$-gridded topographic data are based on the digital elevation model from the Geographical Survey Institute of Japan. Based on the tsunami simulation results, the following items were analyzed and an inundation diagram for each regional coast was created and released (available at https://www.pref.okinawa.jp/site/doboku/kaibo/h27tunami/h27tunami b.html).

1) Inundation depth and inundation range,

2) Standard water level,

3) Coastal tsunami height and arrival time,

4) Maximum run-up height at major points on land,

5) Time-series of the water level change due to Tsunami at major points in the coastal area, and

6) Other factors necessary for setting the tsunami damages.

Maximum run-up height was calculated in this assessment at 49 sites in the Miyako and Yaeyama districts. In this paper, total 24 sites where the plausible run-up height was also estimated in [13] (both in Miyako and Yaeyama districts) and the description of O-Toiai-Gaki (in Miyako District only, [11]) were selected for comparison. Figure 2 shows the location of these sites on the map. Table 2 and Table 3 show the list of the site numbers and the station names for Miyako and Yaeyama districts, respectively. In each district, the stations are numbered clockwise from the eastern coast of the main islands, as shown in Figure 2.

Table 1. Parameters of the faults used for "the 2015 Tsunami Assessment". Fault \#16 is the linkage of Fault \#1 - 3 at the same time $(\mathrm{Mw}=9.0)$.

\begin{tabular}{ccccccccc}
\hline Fault \# & $\begin{array}{c}\text { Depth } \\
(\mathrm{km})\end{array}$ & $\begin{array}{c}\text { Strike } \\
\left(^{\circ}\right)\end{array}$ & $\begin{array}{c}\text { Dip } \\
\left(^{\circ}\right)\end{array}$ & $\begin{array}{c}\text { Rake } \\
\left({ }^{\circ}\right)\end{array}$ & $\begin{array}{c}\text { Length } \\
(\mathrm{km})\end{array}$ & $\begin{array}{c}\text { Width } \\
(\mathrm{km})\end{array}$ & $\begin{array}{c}\text { Slip } \\
(\mathrm{m})\end{array}$ & Mw \\
\hline 1 & 2 & 280 & 12 & 90 & 270 & 70 & 20 & 8.7 \\
2 & 2 & 265 & 12 & 90 & 300 & 70 & 20 & 8.8 \\
3 & 2 & 235 & 12 & 90 & 300 & 70 & 20 & 8.8 \\
\hline
\end{tabular}


Table 2. List of location of each station at which the tsunami run-up height was estimated in Miyako District (a) and Yaeyama District (b).

(a)

\begin{tabular}{|c|c|c|}
\hline Island Name & Site No. & Station Name \\
\hline \multirow{4}{*}{ Miyako Island } & 01 & Shimajiri Port \\
\hline & 05 & Tomori \\
\hline & 06 & Miyaguni \\
\hline & 08 & Hirara Port \\
\hline \multirow[t]{2}{*}{ Ikema Island } & 10 & Ikema \\
\hline & 12 & Sarahama \\
\hline \multirow[t]{2}{*}{ Irabu Island } & 13 & Irabu \\
\hline & 14 & Sawada \\
\hline Minna Island & 16 & Minna Port \\
\hline Tarama Iskand & 17 & Maedomari Port \\
\hline \multicolumn{3}{|c|}{ (b) } \\
\hline Island Name & Site No. & Station Name \\
\hline \multirow{11}{*}{ Ishigaki Island } & 22 & Inoda \\
\hline & 24 & Shiraho \\
\hline & 25 & Miyara Bay \\
\hline & 26 & Ohama \\
\hline & 27 & Tonoshiro Port \\
\hline & 28 & Ishigaki Port \\
\hline & 29 & Nakura Bay \\
\hline & 30 & Kabira Bay \\
\hline & 31 & Urasoko Bay \\
\hline & 33 & Funakuyah Port \\
\hline & 34 & Hirakubo \\
\hline Taketomi Island & 35 & Taketomi East Port \\
\hline Kuro Island & 38 & Miyazato \\
\hline Uechi Island & 43 & Uechi \\
\hline
\end{tabular}

Table 3. Estimation of the run-up height based on the Fault Number 16 in Miyako District. Unit in $\mathrm{m}$. In the column "Plausible run-up height", $\left(^{\star}\right)$ is from [11] and others from [13]. "Remarks" shows ambiguity of the plausible run-up height estimation.

\begin{tabular}{cccc}
\hline Site No. & Plausible run-up height & Maximum run-up height in [14] & Remarks \\
\hline 01 & $8\left(^{*}\right)$ & 17.6 & $>8\left(^{*}\right)$ \\
05 & 13.8 & 28.3 & $9.5-18.1$ \\
06 & $11\left(^{*}\right)$ & 26.5 & \\
08 & 6 & 12.5 & \\
10 & 10 & 17.3 & \\
12 & $11\left(^{*}\right)$ & 13.4 & \\
13 & 7 & 25.9 & $>9.4$ \\
14 & 11 & 15.3 & \\
16 & 9.4 & 21.2 & \\
17 & 15 & 22.3 & \\
\hline
\end{tabular}




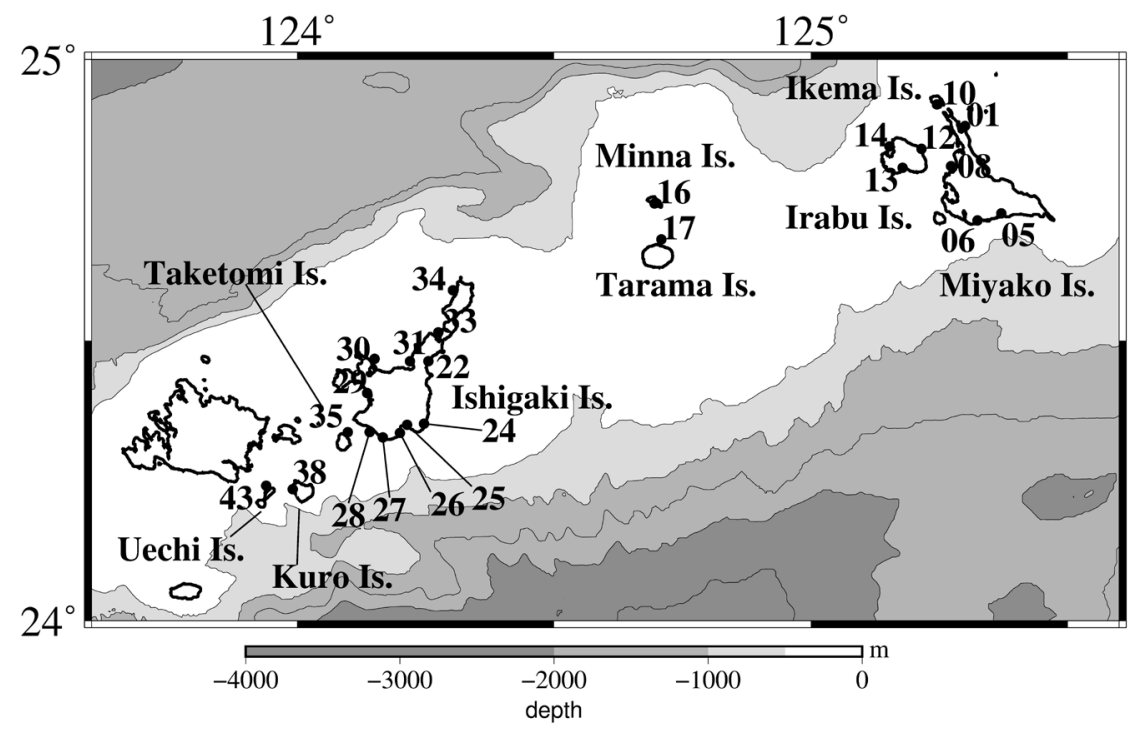

Figure 2. Island names and stations where the tsunami run-up heights between those by [14] and those by the plausible model [11], [13] are examined in this study. "Is." stands for "Island." Station numbers are derived from those in [14] but the only locations which coincide with the plausible model [11], [13] are plotted.

\section{Result}

Table 3 and Table 4 show the comparison between the plausible run-up height ([11] and [13]) and the estimation of the run-up height based on the Fault Number 16 (linkage of 3 faults of $270 \mathrm{~km}-300 \mathrm{~km}$-long each in Figure 1) in the 2015 Tsunami Assessment [14] in Miyako and Yaeyama districts, respectively. In the column "Plausible run-up height", $\left({ }^{*}\right)$ is from the description of O-Toiai-Gaki [11] and others from [13]. "Remarks" shows ambiguity of the plausible run-up height estimation in these studies. Table 5 and Table 6 are the same as Table 3 and Table 4 based on the Fault Number 2 in Figure 1. Figures 3-6 are the plot of these run-up heights for comparison between the result of the 2015 Tsunami Assessment [14] and the plausible run-up height, corresponding to Tables 3-6 but re-arranged by district. The black lines show the result of the 2015 Tsunami Assessment [14] and the grey lines the plausible run-up height with ambiguity ([11] and [13]) in each of these figures.

\subsection{Miyako District}

The result of the 2015 Tsunami Assessment [14] shows completely higher tsunami run-up in the Miyako District. Especially, along the coast of Miyako Island, at Shimajiri Port (Site 01) on the eastern coast, at Tomori (Site 05) and Miyaguni (Site 06) on the southern coast, at Hirara Port (Site 08) on the western coast, the plausible run-up height is almost half of those by the 2015 assessment. At Irabu (Site 13, on the southern coast of Irabu Island) the plausible run-up height is less than one third compared with that by the 2015 Tsunami Assessment [14]. Also, at Minna Port (site 16, Minna Island) on the southern coast of the island, the plausible height is almost half of those by the 2015 assessment. The ratio of the 
Table 4. Same as Table 3 based on the Fault Number 16 in Yaeyama District.

\begin{tabular}{cccc}
\hline Site No. & Plausible run-up height & Maximum run-up height in [14] & Remarks \\
\hline 22 & 7 & 29.9 & $>7$ \\
24 & 22 & 20.4 & \\
25 & 27.3 & 23.9 & $21.4-33.2$ \\
26 & 16 & 21.6 & $9.3-22.6$ \\
27 & 9 & 16.4 & \\
28 & 12 & 14.6 & \\
29 & 3 & 6.9 & \\
30 & 2 & 11.0 & $9.4-29.3$ \\
31 & 2 & 14.1 & \\
33 & 19.4 & 19.4 & \\
34 & 6 & 8.6 & $3.5-13.1$ \\
35 & 5 & 11.3 & \\
38 & 7 & 11.0 & \\
43 & 8.3 & 10.5 & \\
\hline
\end{tabular}

Table 5. Estimation of the run-up height based on the Fault Number 2 in Miyako District. Unit in $\mathrm{m}$. In the column "Plausible run-up height", $\left.{ }^{*}\right)$ is from [11] and others from [13]. "Remarks" shows ambiguity of the plausible run-up height estimation.

\begin{tabular}{cccc}
\hline Site No. & Plausible run-up height & Maximum run-up height in $[14]$ & Remarks \\
\hline 01 & $8\left(^{*}\right)$ & 7.8 & $>8\left(^{*}\right)$ \\
05 & 13.8 & 23.2 & $9.5-18.1$ \\
06 & $11\left(^{*}\right)$ & 21.4 & \\
08 & 6 & 9.5 & \\
10 & 10 & 10.7 & \\
12 & $11\left(^{*}\right)$ & 12.2 & \\
13 & 7 & 24.6 & \\
14 & 11 & 14.4 & \\
\hline
\end{tabular}

Table 6. Same as Table 5 based on the Fault Number 2 in Yaeyama District.

\begin{tabular}{cccc}
\hline Site No. & Plausible run-up height & Maximum run-up height in [14] & Remarks \\
\hline 22 & 7 & 29.9 & $>7$ \\
24 & 22 & 21.0 & \\
25 & 27.3 & 24.2 & $21.4-33.2$ \\
26 & 16 & 22.3 & $9.3-22.6$ \\
27 & 9 & 16.7 & \\
28 & 12 & 14.9 & \\
29 & 3 & 7.3 & \\
30 & 2 & 10.1 & \\
\hline
\end{tabular}




\section{Continued}

\begin{tabular}{lccc}
\hline 31 & 2 & 10.3 & \\
33 & 19.4 & 17.9 & $9.4-29.3$ \\
34 & 6 & 7.6 & \\
35 & 5 & 11.8 & \\
38 & 7 & 10.8 & $3.5-13.1$ \\
43 & 8.3 & 10.9 & \\
\hline
\end{tabular}

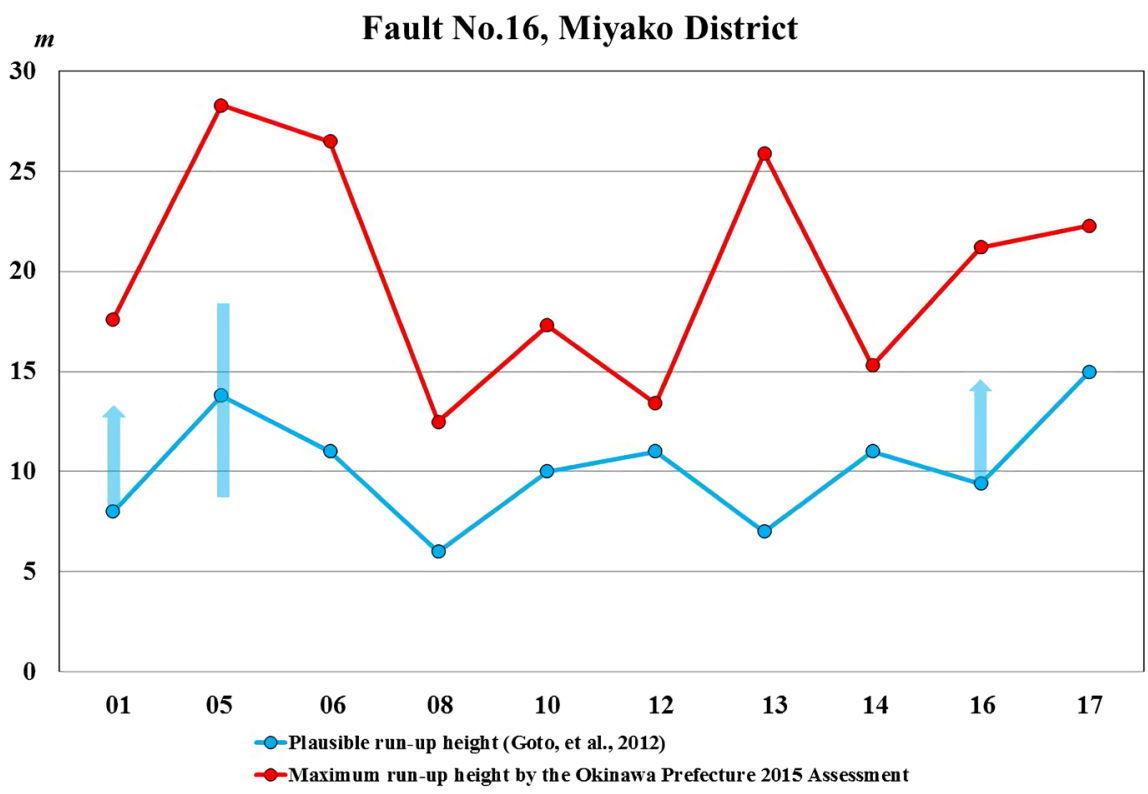

Figure 3. Plot of the plausible run-up height with ambiguity (grey) and the result of the 2015 Tsunami Assessment [14] based on the Fault Number 16 (black) in Miyako District.

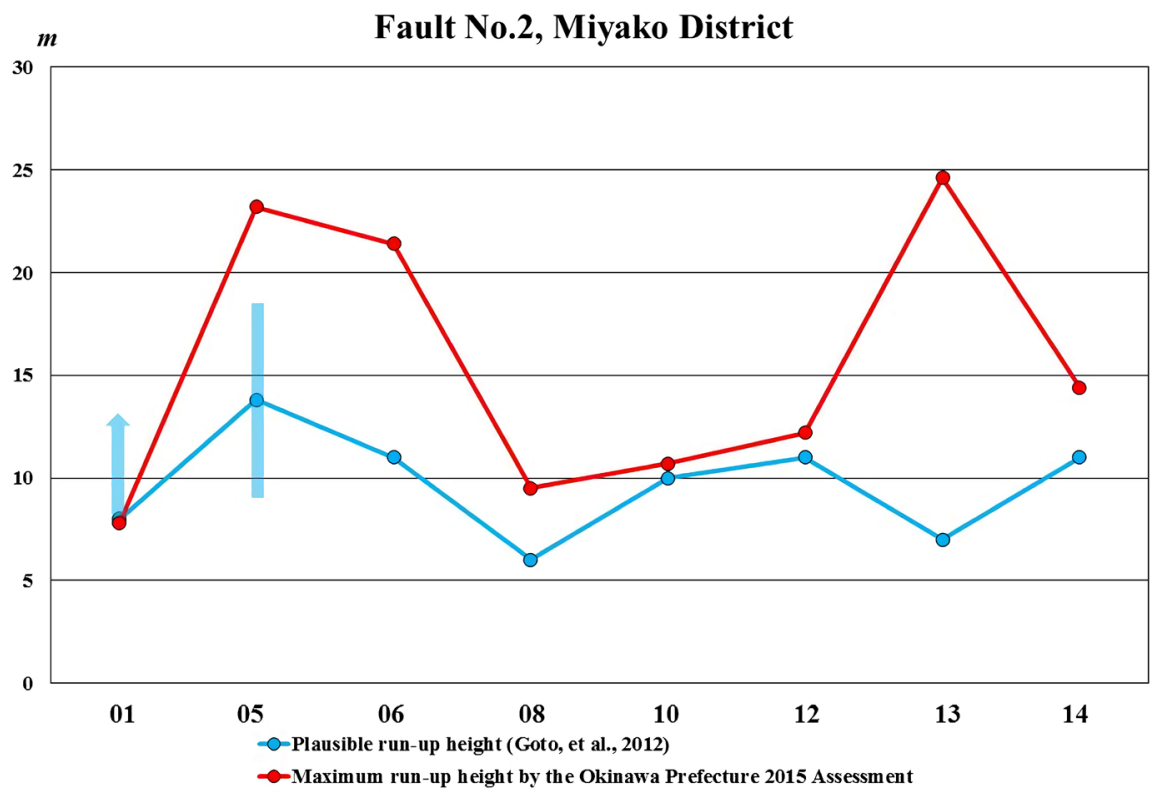

Figure 4. Plot of the plausible run-up height with ambiguity (grey) and the result of the 2015 Tsunami Assessment [14] based on the Fault Number 2 (black) in Miyako District. 


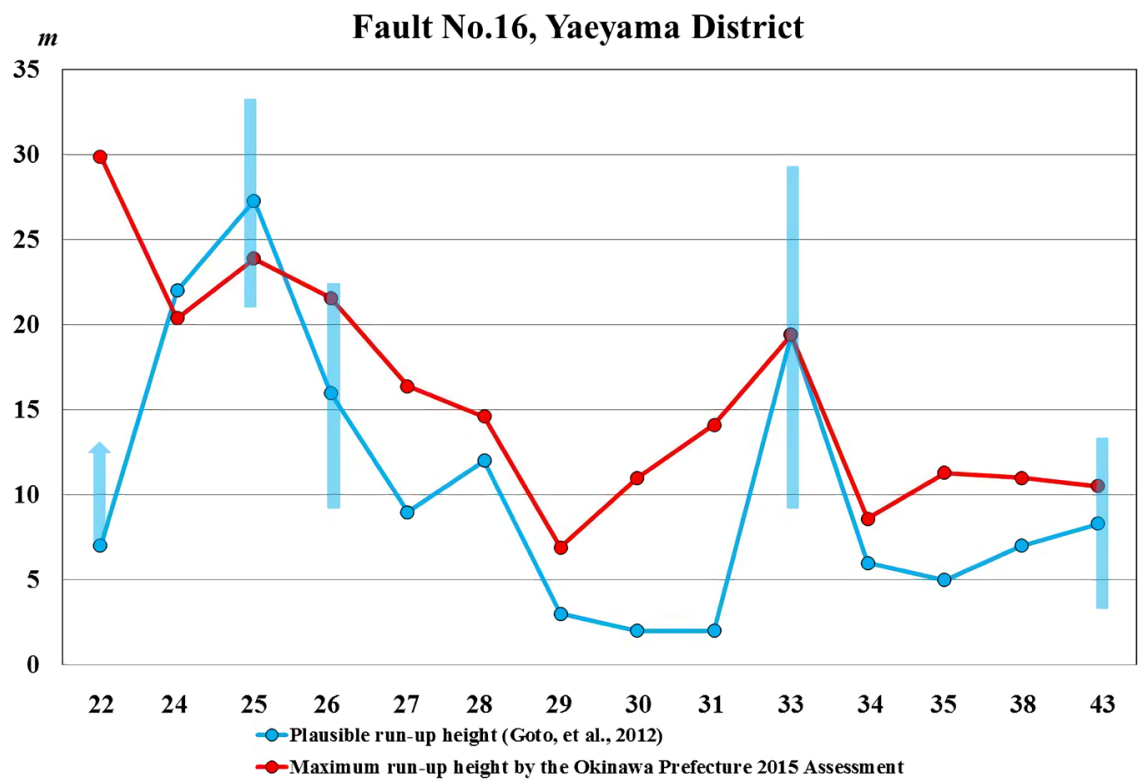

Figure 5. Plot of the plausible run-up height with ambiguity (grey) and the result of the 2015 Tsunami Assessment [14] based on the Fault Number 16 (black) in Yaeyama District.

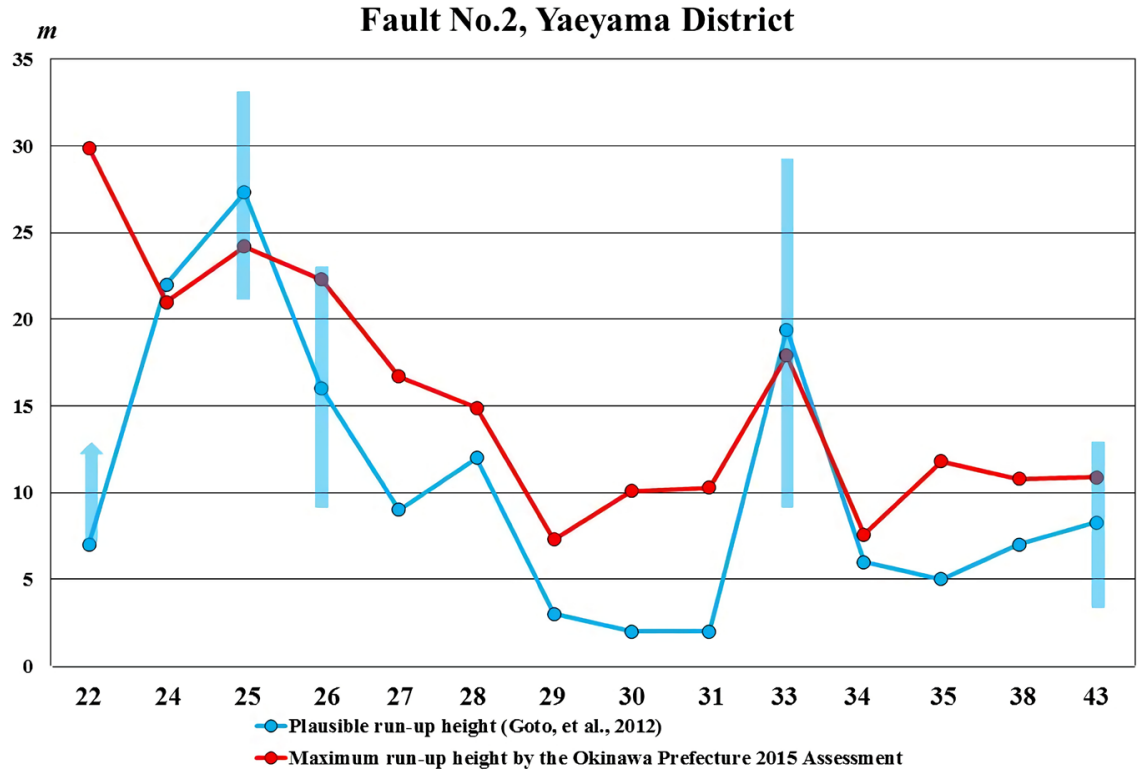

Figure 6. Plot of the plausible run-up height with ambiguity (grey) and the result of the 2015 Tsunami Assessment [14] based on the Fault Number 2 (black) in Yaeyama District.

plausible run-up height to that by the 2015 Tsunami Assessment [14] is about 0.4 for Miyako Island, about 0.7 for Irabu Island, and about 0.6 for Tarama/Minna Islands. The average of the plausible run-up height in the whole Miyako District is about 10m irrespective of the location. However, the 2015 Assessment [14] shows that the run-up height exceeds $20 \mathrm{~m}$ along the southern coast facing the earthquake fault. On the other hand, the run-up height is about $15 \mathrm{~m}$ (Fault Number 16) and about $10 \mathrm{~m}$ (Fault Number 2) along the passage 
between Miyako and Irabu Island, and on the northern coast of both Miyako and Tarama Island.

\subsection{Yaeyama District}

Unlike Miyako District, the pattern and the absolute values of the run-up height by the 2015 Tsunami Assessment [14] are similar to those by the plausible run-up height with a couple of exceptions at Inoda (Site 22) on the eastern coast of Ishigaki Island and Kabira Bay (Site 30) and Urasoko Bay (Site 31) on the northern coast of the southern part of Ishigaki Island.

Shiraho (Site 24), Miyara Bay (Site 25), and Ohama (Site 26) record the maximum run-up height by the plausible model and maximum exceeds $27 \mathrm{~m}$ with the ambiguity of about $\pm 6 \mathrm{~m}$. This area is facing the earthquake fault and a lot of channels/valleys are located off the southern coast of Yaeyama District, unlike Miyako District. One of the valleys is connected to the Miyara River the mouth of which is the Miyara Bay (Site 25). This structure of both on-land and offshore topography might trigger the enormous run-up height. In contrast to this, Site $29-31$ are characterised by low run-up height $(2-3 \mathrm{~m})$.

In Yaeyama district, the ratio of the plausible run-up height to that by the 2015 Tsunami Assessment [14] is about 0.8 at Ishigaki port on the south coast, about 0.6 at Tonoshiro fishing port, about 0.4 at Nakura Bay on the north coast, and about 0.2 at Kabira Bay. On the other hand, in Shiraho, Miyara Bay, and Ohama on the south coast of Ishigaki Island, and Taketomi Kuro and Uechi islands located off the southwestern coast of Ishigaki Island, the results are almost consistent with those by the 2015 Tsunami Assessment [14] (20 - $24 \mathrm{~m})$. The discrepancies between the plausible run-up height $(7 \mathrm{~m})$ and the result by the 2015 Tsunami Assessment [14] (29.9 m) on the eastern coast is unclear.

\section{Discussion}

In this study the plausible tsunami run-up height was compared with the result by [14] in both cases of the Fault number 16 (3 linkage of the fault of $270 \mathrm{~km}$ $300 \mathrm{~km}$-long: corresponding to M9-class earthquake) and the Fault number 2 (a single $300 \mathrm{~km}$-long: M8.8 earthquake). The results show no significant difference in both Miyako and Yaeyama districts. Therefore, it is enough to consider the $300 \mathrm{~km}$-long single fault as the source of the 1771 tsunami. However, it should be noted that the assumption of the slip of the fault used in [14] was uniform and was $20 \mathrm{~m}$ (Table 1) and that the plausible run-up height in the Miyako District is on the whole half of the 2015 assessment under this assumption. If the 1771 tsunami is to be attributed to the earthquake fault off Miyako and Yaeyama districts along the Ryukyu Trench, for both cases of the linkage of the 3 faults and a single fault, the actual slip off Miyako is to be estimated to be some $8-14$ $\mathrm{m}$ whereas the slip off Yaeyama is $20 \mathrm{~m}$.

On the other hand, considering the maximum run-up height in and around Miyara Bay on the south coast of Ishigaki Island, an underwater landslide on the 
southern slope of the "Kuroshima Knoll" located about $40 \mathrm{~km}$ south of Ishigaki Island might be taken into account in addition to an earthquake fault because the underwater landslide might drive a possible local tsunami run-up. In [14], the assumption of inundation caused by submarine landslide on the southern slope of the Kuroshima Knoll leads to the maximum run-up height of $16 \mathrm{~m}$ on the southern coast of Ishigaki Island ([14]). Also, [15] proposed a new hypothesis of a large-scale collapse of the accretionary prism as a possible source of the 1771 tsunami. This also might be triggered by the earthquake fault slip.

\section{Conclusions}

The 2015 Tsunami Assessment [14] assumes the largest possible tsunami based on the records of past earthquakes and tsunami damage in the Okinawa Prefectural region after the Great East Japan Earthquake that occurred on March 11, 2011. Then, the position and parameters of the faults were assumed for the simulation of tsunami propagation. As a result, the inundation depth and run-up height of the probable tsunami caused by the assumed earthquake faults were obtained at the whole coastal area of all the local governments facing the sea. These results are used for tsunami hazard maps of each local government.

Historically, there are no records of huge earthquakes or tsunamis in Okinawa District (the northernmost part of Okinawa Prefecture). Then it is unclear whether tsunami damage of the expected scale in [14] will actually take place in the future. However, the results of [14] may be fully utilised for tsunami preparedness also in this district where was hit by a distant tsunami when the Great Chilean earthquake occurred.

\section{Acknowledgements}

The author thanks Coastal Disaster Prevention Division, Civil Engineering Department, Okinawa Prefecture for inviting him as a member of the Review Committee of the 2015 Tsunami Assessment Project. The author also thanks the other members of the Review Committee, especially Prof. Seikou Tsukayama (Professor Emeritus, University of the Ryukyus), Chairperson of the Committee for fruitful discussion during the committee meetings.

\section{Conflicts of Interest}

The author declares no conflicts of interest regarding the publication of this paper.

\section{References}

[1] National Astronomical Observatory of Japan (2021) Chronological Scientific Tables (Rika-Nenpyo 2021). 1174 p. (in Japanese)

[2] Makino, K. (1968) The Meiwa Tsunami at Yaeyama. Published by Author, Ishigaki, 462 p. (In Japanese)

[3] Hamamoto, F., Sakurai, M. and Nagano, M. (1979) Submarine Geology off the 
Miyako and Yaeyama Islands. Report of Hydrographic Researches, 14, 1-38. (In Japanese)

[4] Matsumoto, T. and Kimura, M. (1993) Detailed Bathymetric Survey in the Sea Region of the Estimated Source Area of the 1771 Yaeyama Earthquake Tsunami and Consideration of the Mechanism of Its Occurrence. Journal of the Seismological Society of Japan 2 nd Ser., 45, 417-426. (In Japanese)

[5] Hiyoshi, Y., Ando, M. and Kimura, M. (1986) Generation Mechanism of the 1771 Nanseishoto Great Meiwa Tsunami-Generation of a Large-Scale Underwater Landslide. Abstract Volume of the Annual Meeting of the Seismological Society of Japan, 80.

[6] Hiraishi, T., Shibaki, H. and Hara, N. (2001) Numerical Simulation of Meiwa-Yaeyama Earthquake Tsunami in Landslide Model with Circular Rupture. Proceedings of Coastal Engineering, 48, 351.

[7] Imamura, F., Yoshida, I. and Moore, A. (2001) Numerical Study of the 1771 Meiwa Tsunami at Ishigaki Island, Okinawa and the Movement of the Tsunami Stones. Proceedings of Coastal Engineering, 48, 346-350. (In Japanese)

[8] Nakamura, M. (2006) Source Fault Model of the 1771 Yaeyama Tsunami, Southern Ryukyu Islands, Japan, Inferred from Numerical Simulation. Pure and Applied Geophysics, 163, 41-54. https://doi.org/10.1007/s00024-005-0007-9

[9] Matsumoto, T., Shinjo, R., Nakamura, M., Doi, A., Kimura, M., Ono, T. and Kubo, A. (2009) Submarine, Across-Arc Normal Fault System in the Southwest Ryukyu Arc Triggered the 1771 Tsunami Hazard? Field Evidences from Multibieam Survey and In-Situ Observation by ROV. Polish Journal of Environmental Studies, 18, 123-129.

[10] Kawana, T. and Nakata, T. (1994) Timing of Late Holocene Tsunamis Originated around the Southern Ryukyu Islands, Japan, Deduced from Coralline Tsunami Deposits. Journal of Geography, 103, 352-376. (In Japanese)

[11] Kato, Y. (1989) The Yaeyama Earthquake Tsunami in the Miyako District as Described in the Newly Discovered Record "O-Toiai-Gaki"'. Bulletin of the Faculty of Science, University of the Ryukyus, 47, 153-158. (In Japanese)

[12] Matsumoto, T. (2016) Re-Estimation of Damages in the Miyako District Okinawa by 1771 Great Meiwa Tsunami. Japan Geoscience Union Meeting 2016, Chiba Japan, 25 May 2016, HDS19-P04.

[13] Goto, K., Miyazawa, K., Adaniya, A., Kakinohana, S., Kugai, Y., Shimabukuro, A., Shimabukuro, N., Masaki, Y., Matsushima, S. and Miyagi, K. (2012) Re-Estimation of the Run-Up Height of the 1771 Great Meiwa Tsunami, II: The Whole Sakishima Area. Research Report of Tsunami Engineering, 29, 129-146. (In Japanese)

[14] Okinawa Prefecture (2015) Okinawa Prefecture Tsunami Inundation Assumption Setting Outsourcing Report. (In Japanese) https://www.pref.okinawa.jp/site/doboku/kaibo/h27tunami/h27tunami b.html

[15] Okamura, Y., Nishizawa, A., Fujii, Y. and Yanagisawa, H. (2018) Accretionary Prism Collapse: A New Hypothesis on the Source of the 1771 Giant Tsunami in the Ryukyu Arc, SW Japan. Scientific Reports, 8, Article No. 13620. https://doi.org/10.1038/s41598-018-31956-8 